\title{
SensiBlend: Sensing Blended Experiences in Professional and Social Contexts
}

\author{
Himanshu Verma \\ TU Delft \\ Netherlands \\ H.Verma@tudelft.nl
}

\author{
Marios Constantinides \\ Nokia Bell Labs \\ United Kingdom \\ marios.constantinides@nokia-bell- \\ labs.com
}

\author{
Sailin Zhong \\ University of Fribourg \\ Switzerland \\ sailin.zhong@unifr.ch
}

\author{
Abdallah El Ali \\ CWI Amsterdam \\ Netherlands \\ abdallah.el.ali@cwi.nl
}

\author{
Hamed S. Alavi \\ University of Fribourg \\ Switzerland \\ hamed.alavi@unifr.ch
}

\begin{abstract}
Unlike traditional workshops, SensiBlend is a living experiment about the future of remote, hybrid, and blended experiences within professional and other social contexts. The interplay of interpersonal relationships with tools and spaces-digital and physical-has been abruptly challenged and fundamentally altered as a result of the COVID-19 pandemic. With this meta-workshop, we seek to scrutinize and advance the role and impact of Ubiquitous Computing in the new "blended" social reality, and raise questions relating to the specific attributes of socio-technical experiences in the future organization of interpersonal relationships. How do we better equip people to deal with blended experiences? What dimensions of socio-technical experiences are at stake? To this end, we will utilize the occasion of a virtual UbiComp in combination with novel remote-working tools and participatory sensing with attendees to collectively examine, discuss, and elicit the potential routes of augmenting social practices in a discourse about the future of blended working, socializing, and living.
\end{abstract}

\section{CCS CONCEPTS}

- Human-centered computing $\rightarrow$ Ubiquitous and mobile computing.

\section{KEYWORDS}

Remote Work and Socializing, Hybrid Arrangements, Blended Experiences, Participatory Sensing, Future Workshops

\section{ACM Reference Format:}

Himanshu Verma, Marios Constantinides, Sailin Zhong, Abdallah El Ali, and Hamed S. Alavi. 2021. SensiBlend: Sensing Blended Experiences in Professional and Social Contexts. In Adjunct Proceedings of the 2021 ACM International foint Conference on Pervasive and Ubiquitous Computing and Proceedings of the 2021 ACM International Symposium on Wearable Computers

Permission to make digital or hard copies of all or part of this work for personal or classroom use is granted without fee provided that copies are not made or distributed for profit or commercial advantage and that copies bear this notice and the full citation on the first page. Copyrights for components of this work owned by others than the author(s) must be honored. Abstracting with credit is permitted. To copy otherwise, or republish, to post on servers or to redistribute to lists, requires prior specific permission and/or a fee. Request permissions from permissions@acm.org.

UbiComp-ISWC '21 Adjunct, September 21-26, 2021, Virtual, USA

(C) 2021 Copyright held by the owner/author(s). Publication rights licensed to ACM. ACM ISBN 978-1-4503-8461-2/21/09..\$15.00

https://doi.org/10.1145/3460418.3479268
(UbiComp-ISWC '21 Adjunct), September 21-26, 2021, Virtual, USA. ACM, New York, NY, USA, 5 pages. https://doi.org/10.1145/3460418.3479268

\section{BACKGROUND}

The COVID-19 pandemic can be regarded as the most disruptive global event that has fundamentally altered our-individual and collective-living, working, and learning practices. It has forced the world into a prolonged natural experiment that has tested and mainstreamed what researchers and visionaries have been talking about for decades-the ubiquity of working and interacting remotely. Remote work, however, is not a new construct. In fact, the first attempts to ignite it date back to the idea of "telecommuting" [6] as a solution to traffic tangles and limited resources. Since then, organizations began officially experimenting with flexible work arrangements, from 'work from home' to 'work from anywhere'. However, the global forces that suddenly transformed our personal, professional, and social lives into a makeshift manifestation of " $a$ new (remote) normal", also brought opportunities to re-imagine and augment the emerging reality full of blended experiences.

In a highly interconnected and globalized world, while an abundance of tools and technological solutions enabled encounters for geographically distributed teams, these tools were not envisaged as an extended and sustained means of working, learning, or socializing $[5,7]$. Moreover, our "pre-COVID" reality afforded an auxiliary and rather peripheral position to remote engagements, which were often reflected in our co-located social customs and routines. In addition, research efforts had not have the opportunity to examine the context of entirely remote social experiences, their extended effects and how these permeate to other aspects of people's lives (e.g., mental well-being or work-life balance). Now, organizations are enthusiastically embracing the long-term possibilities of remote working [2, 9]. Also, educational institutions are experimenting with extended periods of remote and hybrid learning [8, 11], and organizers are finding creative ways of replicating and reinventing the interpersonal interactions during online forums, workshops, and conferences $[1,3,10]$; these hybrid (working/learning) arrangements are envisaged as a viable way forward-an ideal compromise.

These hybrid arrangements represent the malleable distribution of an individual's social and professional reality-in both time and activity-situated somewhere within the spectrum from completely virtual to completely physical. Effective manifestations of this hybrid social reality entails designing for blended social experiences, 
which amalgamate responsible sensing methods with responsive and context-aware tools and services, and enable people to meaningfully navigate within their professional and social organization.

For the sake of clarity, we distinguish hybrid arrangements from blended experiences as follows: while the hybrid arrangement corresponds to an individual's preferences around self-organization, blended experiences are the embodiment of the interactions between tools, space and practices. In addition, from the perspective of organizations and educational institutions, hybrid arrangements (e.g., partial work-from-home) are related to the effective governance of resources (e.g., number of work places or equipment), and during the COVID-19 pandemic, ensured the health and safety of its members. Blended-working/learning-experiences, as illustrated previously, encompass the dynamic and diverse ways in which the hybrid arrangements interact with digital tools and spaces to evoke a perception of social facilitation [12]-an "appropriated" and rather "simulated" togetherness. To exemplify our distinction, we can think of blended learning as separate from hybrid schools. These two notions, however, are fundamentally inter-dependent and have become highly relevant as we reassess the current social and professional constructs and contracts, and raise numerous challenges and questions that we seek to address in this workshop. How can we leverage existing technological modalities, including conversational interfaces, eXtended reality, soft robotics, smart garments, to support and scale the hybrid arrangements and the blended experiences they afford? What are the new and creative possibilities for technological interventions that enable users to meaningfully connect to peers, or distribute their blended social experiences on mundane objects (e.g., social prosthesis) or new forms of interfaces? How do we adapt our sensing approaches and apply our research methods "in-the-wild" as we transition into the realm of blended experiences and flexible working/learning? How do we sense and measure people's physiological and social responses (cf., [4]) to these blended experiences (e.g., isolation, fatigue, stress, burnout)? How do we design responsible and ethical sensing mechanisms which enable awareness of people's mental and physical well-being, while discouraging acts of surveillance and breach of privacy? Essentially, how do we better equip people to deal with blended experiences?

Besides these aforementioned questions which hold significance for the UbiComp community, there are several challenges which extend to other disciplines. For instance, how can sensing and actuation embodied by built environments of the future create opportunities for hosting virtual social events? How can AR and VR experiences complement the physical architectural elements to support virtual conferencing? What will be the envisaged consequences of blended social on the future of urbanity and mobility?

\section{SENSIBLEND WORKSHOP}

SensiBlend is a unique workshop as compared to traditional workshops, in terms of format and objectives. SensiBlend is both a metaworkshop and a living experiment. As a meta-workshop, it seeks to scrutinize the future of remote, hybrid, and blended experiences within professional and social contexts-not just limited to interpersonal interactions at work or beyond, but also extending to forums, workshops, and conferences-and how they interact with tools and spaces. As a living experiment involving the attendees of the workshop, we aim to employ novel remote-working tools and participatory sensing of attendees' physical and physiological attributes, to elicit potential routes of augmenting social practices in a discourse about the future of remote working, learning, and living. We will employ the policy of 'BYODS' - i.e. bring your own devices and sensors, to gather blended experiences during the workshop. The diverse and rich data collected during the workshop about attendees' perceptions and experiences will be a valuable resource for future analysis (done collaboratively with all the participants), and importantly, an evidence-based repertoire of blended experiences and ground-truths to design novel technological interventions as well as to guide the agenda for future discourses and research.

We aim SensiBlend to be an interdisciplinary forum that brings together researchers and practitioners from academia and industry. We expect participants from the domains of Ubiquitous Computing, $\mathrm{HCI}$, ICMI, CSCW, but also from the disciplines of Industrial Design, Social Cognition, Architecture, and Urban Sciences. In particular, the goal of this workshop is to collaboratively:

- Assess the evolving socio-technical themes, concerns, and unanswered questions in relation to remote and rather isolated interpersonal and professional interactions, followed by developing them into clusters which are shared and critiqued among workshop attendees.

- Depict the space of design possibilities in terms of technological and environmental interventions.

- Envision new sensing and data-acquisition paradigms to responsibly and accurately gather physical, physiological, and experiential qualities.

- Explore novel and hybrid methods for experimentation "inthe-wild" which are adapted to blended experiences.

- More generally, start a discourse around the future of "blended social" and co-create research agenda(s) for meaningfully addressing it.

- Finally, consolidate an international network of researchers to further develop these research agendas through funding proposals and through steering future funding instruments.

Relevance and impact to UbiComp. We consider UbiComp as an enabler of the new experiential and generative possibilities within the realm of the new blended social, as hybrid working and socializing become ever more pervasive. UbiComp's role and impact is particularly pronounced in a) facilitating the development of a comprehensive understanding of the emerging nature of blended social experiences, its perception by diverse actors, and its relationship with other aspects of people's lives (such as work-life balance, mental well-being, active living, etc.), b) designing creative sensory and technological interventions which offer enriching experiences in the era of hybrid social arrangements (at work and beyond), and more importantly to $c$ ) enable other stakeholders (organizations, policy makers, health-care professionals) to make data-driven, responsible, and evidence-based policy decisions which are attuned to people's needs, experiences, and expectations.

In this regard, UbiComp, with its strong community engaged in several themes (such as sensing, modeling, context- and socialawareness, ambient intelligence, AI/ML etc.), as well as its synergistic and multi-disciplinary coalitions with research and industry 
across varied domains (Architecture, Urban Sciences, Health Informatics, Industrial Design) afford it a crucial role to pave the way for concerted multi-stakeholder efforts in enabling blended experiences. Furthermore, owing to its strong dependence on sensing and technological interventions, these blended experiences may be at the risk of exposure to harmful and unethical activities that can put peoples' rights and dignity at risk (for example, through workplace surveillance). Therefore, organizing this workshop at UbiComp, with a balanced participation of industry and academic researchers, is a unique opportunity towards the principles of ethics, responsibility, and privacy at a crucial time when blended experiences are increasingly proliferating.

Long-term objectives. This workshop will contribute to a deeper understanding of challenges, concerns, and opportunities surrounding the hybrid social arrangements and blended experiences they afford. It will open up the avenues for the assimilation, infusion and nurturing of multi-disciplinary perspectives and paradigms typically ascribed to research communities beyond UbiComp and HCI (such as Architecture, Industrial Design, Social Cognition). Moreover, the post-workshop participatory analysis of the acquired sensory data will manifest in a repertoire of blended social experiences, ground truths, and more importantly a rich resource of actionable insights about the future organization of virtual workshops and conferences. Finally, the results of the participatory (multi-perspective) analysis by workshop participants, as well as the developed research agendas and their collaborative follow-ups will be invited to submit in an open call to a special issue or a book (for example, IEEE Pervasive, ACM ToCHI or Springer's Personal \& Ubiquitous Computing) shortly after the conclusion of the workshop.

\section{WORKSHOP STRUCTURE}

Workshop topics. The workshop is intended to be a forum to share ideas that will help shape the future of interpersonal interactions at work and beyond, and to rethink the role of UbiComp as an enabler of new experiential and generative possibilities within the realm of the new blended experiences likely to emerge due to hybrid work and social arrangements. The main topics of interest include, but are not limited to:

- Development of robust models that capture people's psychological aspects and social response to remote/hybrid arrangements (e.g., isolation, fatigue, stress, or burnout)

- Methods and techniques for conducting in-the-wild studies, remote/hybrid data collection, and multi-modal sensing

- Re-imagining creative and novel technological modalities to support blended experiences (e.g., conversational interfaces, wearables, textiles, eXtended reality)

- Evaluation of security, privacy, and workplace surveillance in developing UbiComp technologies for blended experiences

Workshop format. We plan for a full-day virtual workshop with submissions (4-6 pages, excluding references) that include completed and ongoing research works as well as position papers. The workshop will take place primarily over Zoom ${ }^{1}$, where we will additionally use Miro $^{2}$ for collaborative (synchronous) activities,

\footnotetext{
${ }^{1}$ https://zoom.us/

${ }^{2}$ https://miro.com/
}

Table 1: Proposed schedule for the SensiBlend workshop

\begin{tabular}{|c|c|c|}
\hline & Time & Activity \\
\hline \multirow{9}{*}{ 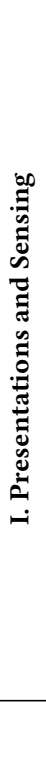 } & 08:45-09:00 & $\begin{array}{l}\text { Setting Up: Login to the virtual workshop (Zoom) } \\
\text { and greet all the participants. }\end{array}$ \\
\hline & $09: 00-09: 15$ & $\begin{array}{l}\text { Welcome: Introduce organizers, participants, work- } \\
\text { shop objectives and schedule. }\end{array}$ \\
\hline & 09:15-09:30 & $\begin{array}{l}\text { Sensor-Check: Getting the sensors working, check- } \\
\text { ing the data-acquisition, and synchronizing clocks. }\end{array}$ \\
\hline & 09:30-10:00 & Keynote: Presentation by an invited expert. \\
\hline & $10: 00-10: 15$ & $\mathbf{Q} \& \mathrm{~A}$ \\
\hline & $10: 15-10: 30$ & Short Break: Stretch your legs and grab a coffee. \\
\hline & $10: 30-11: 30$ & $\begin{array}{l}\text { Pitch / Flash Presentations: Participants introduce } \\
\text { themselves and present their position/research papers } \\
\text { (approximately } 3 \text { minutes per participant if } \mathrm{N}=20 \text { ). In } \\
\text { addition, we will ask participants to present one re- } \\
\text { search question that they cannot address by them- } \\
\text { selves. Slides will be prepared in advance in Google } \\
\text { Slides or pre-recorded videos. }\end{array}$ \\
\hline & $11: 30-12: 00$ & $\begin{array}{l}\text { Eliciting Themes: A rapid-round of discussion in } \\
\text { break-out rooms to elicit unaddressed questions, con- } \\
\text { cerns and challenges. These illustrations will be added } \\
\text { to a common Miro board. }\end{array}$ \\
\hline & $12: 00-13: 00$ & $\begin{array}{l}\text { Lunch Break (Social gathering on Mozilla Hubs or } \\
\text { Gather Town) }\end{array}$ \\
\hline \multirow{9}{*}{ 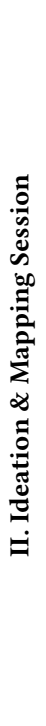 } & $13: 00-13: 10$ & $\begin{array}{l}\text { Cluster Themes: Organizers and participants collec- } \\
\text { tively cluster themes into topics of interests. }\end{array}$ \\
\hline & $13: 10-13: 30$ & $\begin{array}{l}\text { Ideation Session: Small groups within break-out } \\
\text { rooms will brainstorm about one topic of interest, } \\
\text { and add their thoughts on a shared Miro board. }\end{array}$ \\
\hline & $13: 30-14: 00$ & $\begin{array}{l}\text { Group Feedback: Groups present the results of their } \\
\text { ideation to all participants for feedback. }\end{array}$ \\
\hline & $14: 00-14: 15$ & E-coffee Break \\
\hline & $14: 15-14: 45$ & $\begin{array}{l}\text { Mapping Session: Small groups within break-out } \\
\text { rooms and using Miro boards will consolidate their } \\
\text { ideas into developed research agendas. }\end{array}$ \\
\hline & $14: 45-15: 00$ & $\begin{array}{l}\text { Summarize Discussions: Each group prepares a } \\
\text { short presentation to summarize their developed re- } \\
\text { search agendas and how to take them forward. }\end{array}$ \\
\hline & $15: 00-15: 45$ & $\begin{array}{l}\text { Group Presentations: Each group presents and dis- } \\
\text { cusses the results of ideation and mapping session to } \\
\text { all other participants. }\end{array}$ \\
\hline & $15: 45-16: 00$ & Short Break \\
\hline & $16: 00-16: 30$ & $\begin{array}{l}\text { Wrap Up: Summary of the workshop and follow-up } \\
\text { activities (sensory data analysis, future collaborations, } \\
\text { etc.) and take virtual group photos. }\end{array}$ \\
\hline
\end{tabular}

and the Gather Town ${ }^{3}$ or Mozilla Hubs ${ }^{4}$ platforms for facilitating social interaction before, during, and after the workshop. The entire workshop is estimated to be around 8 hours, with varied activities, presentations, and social events as illustrated in Table 1. We will provide how-to tutorials a week before the workshop, in case any of the participants are not familiar with the tools we aim to use.

\footnotetext{
${ }^{3}$ https://gather.town/

${ }^{4}$ https://hubs.mozilla.com/
} 
In the first half, a keynote, (rapid) presentations of accepted works, and a theme elicitation session will be combined with sensory data-acquisition phase. Since SensiBlend is also a living experiment, our attendees will be encouraged to bring their own devices and sensors ('BYODS'), and participate in a collective effort to gather perceptions and experiences while attending a virtual workshop. The collected data-a repertoire of blended experienceswill be collectively analyzed by all the attendees, as one of the post-workshop activities, and may result in a potential publication (article and a dataset). In the second half, the organizers and participants will collectively cluster themes into topics of interest, which will be further developed and consolidated into executable research agendas, in small groups of 3-4 participants and different activities promoting ideation, mapping, and synthesis.

Estimated number of participants. We aim to invite 20-25 participants from diverse domains (UbiComp, HCI, ICMI, CSCW, Architecture, Industrial Design, Social Cognition), both from academia and industry, who are working on themes relevant to the workshop.

Paper selection and publication. Submissions will be peer-reviewed by at least two reviewers (including organizers and external reviewers). Our acceptance criteria will be a mixture of relevance, novelty, provocativeness, and research quality. Given the theme of this workshop, we are confident to attract a large number of paper submissions which enables us to organize a high-quality workshop.

\section{Important dates.}

- Call for Papers (CfP): 15 April 2021

- Paper submission: 15 June 2021

- Notification to authors: 15 July 2021

- Camera-ready deadline: 31 July 2021

- Workshop Day: 25 September 2021

Pre-workshop activities. We will distribute the call for papers (CfP) through the ACM SIGCHI mailing list, our social and professional networks, and the workshop website. Also, in the weeks leading to the workshop, we will reach out to our participants and identify which device(s) or sensor(s) they would like to use, where we ensure seamless setup with them prior to the workshop day. During this time, we will also collect privacy and data protection forms, to ensure informed consent.

Post-workshop activities. During and following the workshop, discussion results and outcomes will be blogged on the workshop website and disseminated in ACM Interactions. Following the workshop, drawing on the workshop submissions and discussions, we will propose a journal special issue (in IEEE Pervasive or ToCHI), or a book in the Springer Series on Ubiquitous and Personal Computing, and encourage participants to collaborate on submissions around the developed research agendas. Moreover, we will setup a repository to share and upload acquired sensor data amongst the attendees, and another one to facilitate collective analysis of this multi-modal data. Finally, the results of this analysis will be consolidated in a journal article co-authored by all the attendees.

\section{ORGANIZERS}

Below are short biographies of each organizer. Expertise and interests are complementary and reflect the interdisciplinary perspectives of the workshop topic.
Himanshu Verma (main contact) is a Tenure-Track Assistant Professor at the Faculty of Industrial Design at TU Delft (Netherlands). He has a background in HCI, UbiComp and Social Cognition. He is interested in examining the social dimensions of wearables, and his current research is focused on facilitating better collaboration between people and AI powered systems situated within our built and urban environments.

Website: https://vermahimanshu.com/

Marios Constantinides is a Research Scientist in the Social Dynamics team at Nokia Bell Labs, Cambridge (UK). He is interested in HCI, mobile-sensing, and user modeling. His current research focuses on understanding psychological aspects of human behavior in the context of workplace and well-being.

Website: https://comarios.com/

Sailin Zhong is a PhD student at the Human-IST Institute, at the University of Fribourg in Switzerland. Her research interest lies in the conjunction of the human sense of comfort and AI through environmental and physiological sensing.

Website: https://sailinzhong.net/

Abdallah El Ali is a Tenure-track Researcher at the Distributed \& Interactive Systems group at Centrum Wiskunde \& Informatica (CWI) in the Netherlands. His research focus is on temporal challenges in eliciting, capturing, and predicting human emotions, specifically on usable and effective emotion elicitation and annotation techniques across environments (VR/AR, mobile, wearables). Website: https://abdoelali.com/

Hamed Alavi is a Lecture at the Human-IST Institute, at the University of Fribourg in Switzerland. His current research is focused on the future of human's interactive experiences with built environments. Particularly, he is interested in the engagement of HCI and UbiComp in the evolution of buildings and urban spaces as they increasingly incorporate $\mathrm{AI}$, context-aware automation, and new form of interactivity. Hamed has previously co-organized CHI workshops in 2016 and 2019, as well as a DIS workshop in 2018.

Website: https://hamedalavi.com/

\section{REFERENCES}

[1] Bon Adriel Aseniero, Marios Constantinides, Sagar Joglekar, Ke Zhou, and Daniele Quercia. 2020. MeetCues: Supporting online meetings experience. In Proc. of the IEEE Visualization Conference.

[2] Jose Maria Barrero, Nicholas Bloom, and Steven J Davis. 2020. Why Working From Home Will Stick. University of Chicago, Becker Friedman Institute for Economics Working Paper 2020-174 (2020).

[3] Jun-Ho Choi, Marios Constantinides, Sagar Joglekar, and Daniele Quercia. 2021. KAIROS: Talking Heads and Moving Bodies for Successful Meetings. In Proceedings of the 22nd International Workshop on Mobile Computing Systems and Applications. 30-36.

[4] Marios Constantinides, Sanja Šćepanović, Daniele Quercia, Hongwei Li, Ugo Sassi, and Michael Eggleston. 2020. ComFeel: Productivity is a Matter of the Senses Too. Proc. Interact. Mob. Wearable Ubiquitous Technol. 4, 4 (Dec. 2020).

[5] Thomas W Malone et al. 2004. The future of work. Audio-Tech Business Book Summaries, Incorporated.

[6] JM Nilles, FR Carlson, P Gray, and G Hanneman. 1974. Telecommunicationstransportation tradeoffs. Final Report (1974).

[7] Gary M Olson and Judith S Olson. 2000. Distance matters. Human-computer interaction 15, 2-3 (2000), 139-178.

[8] Andrzej Ożadowicz. 2020. Modified Blended Learning in Engineering Higher Education during the COVID-19 Lockdown-Building Automation Courses Case Study. Education Sciences 10, 10 (2020), 292.

[9] Adam Ozimek. 2020. The future of remote work. SSRN 3638597 (2020).

[10] Advait Sarkar, Sean Rintel, Damian Borowiec, Rachel Bergmann, Sharon Gillett, Danielle Bragg, Nancy Baym, and Abigail Sellen. 2021. The promise and peril of 
parallel chat in video meetings for work. Proc. CHI 2021 LBW (2021).

[11] Alexander Skulmowski and Günter Daniel Rey. 2020. COVID-19 as an accelerator for digitalization at a German university: Establishing hybrid campuses in times of crisis. Human Behavior and Emerging Technologies 2, 3 (2020), 212-216. [12] Robert B Zajonc. 1965. Social facilitation. Science 149, 3681 (1965), 269-274. 